\title{
Covid - 19 Readiness Organizational Trust Scale
}

\section{Covid - 19 Hazırlılığı Örgütsel Güven Ölçeği}

\author{
Nihal Mamatoğlu ${ }^{1}$, Şeyhmus Aksoy²
}

\begin{abstract}
:
It was aimed to develop a scale to evaluate how trust-distrust is structured in the context at the macro level; the state, lower organizations, employees and organization managers, decisions and measures regarding the epidemic and also communication between the employees and the organization and the changes brought about the way of doing business after being declared the outbreak in Turkey COVID-19. For this purpose, online interviews conducted with the help of open-ended questions. The obtained data transformed into measurable scale items and applied to 150 participants (Male: 78, Female: 72; Age: 22 - 67, Average: 38.3, SS: 12.43) together with the SocioDemographic Information Form, General Job Satisfaction, and Turnover Intention scales. The findings obtained revealed that the scale has a three-factor structure: 'Trust in Manager', 'Trust in Organization' and 'Trust in Employee'. The results of the correlation analysis performed within the scope of the criterion validity showed that all the sub-dimensions of the scale are associated with General Job Satisfaction and the Turnover Intention. The analyzes carried out to test the discrimination validity showed that there is a significant differences in terms of Trust in Organization and Trust in Employees in groups where the perception of work-related health hazard is less dangerous and very dangerous. As a result, the findings obtained in this study show that the COVID - 19 Readiness Organizational Trust Scale is a valid and reliable scale whose psychometric properties have been empirically tested in the Turkish sample.
\end{abstract}

Keywords: Organizational Trust, COVID - 19, COVID - 19 Readiness, Scale Development

${ }^{1}$ Prof., Dr., Bolu Abant Izzet Baysal University, Faculty of Arts and Sciences, Department of Psychology, Bolu-Turkey, Orcid Id: https://orcid.org/0000-0003-1375-6782

${ }^{2}$ MSc, Bolu Abant Izzet Baysal University, Faculty of Arts and Sciences, Department of Psychology, Bolu-Turkey, Orcid Id: https://orcid.org/0000-0001-6637-4126

Address of Correspondence/Yazışma Adresi: Bolu Abant Izzet Baysal University, Faculty of Arts and Sciences, Psychology Department, Bolu-Turkey, E-mail:seyhmus.aksoy1@gmail.com

Date of Received/Geliş Tarihi: 10.03.2021, Date of Revision/Düzeltme Tarihi: 03.05.2021, Date of Acceptance/Kabul Tarihi: 04.08.2021, Date of Online Publication/Çevirimiçi Yayın Tarihi: 01.09.2021

Citing/Referans Gösterimi: Mamatoğlu, N., Aksoy, Ş. (2021). Covid-19 Readiness Organizational Trust Scale, Cyprus Turkish Journal of Psychiatry \& Psychology, 3(2): 183-91

(C) 2021 The Author(s). Published by Cyprus Mental Health Institute / Cyprus Turkish Journal of Psychiatry and Psychology (www.ktppdergisi.com). This article is an open access article distributed under the terms and conditions of the Creative Commons Attribution 4.0 license which permits use, sharing, adaptation, distribution and reproduction in any medium or format, provided the original work is properly cited and is not used for commercial purposes. http://creativecommons.org/licenses/by/4.0/ 


\section{Öz:}

$\mathrm{Bu}$ çalışmada, Türkiye'de COVID-19 salgını ilan edildikten sonra; makro düzeyde devletin, daha aşağıda örgütlerin, çalışanların ve örgüt yöneticilerinin, salgınla ilgili olarak aldığı kararlar, tedbirler, çalışanların kendi aralarında ve örgütle kurduğu iletişim, iş yapma tarzı ile ilgili getirilen yenilikler bağlamında çalışan ve örgüt arasında kurulan güven-güvensizliğin nasıl yapılandığını değerlendirmeye yönelik bir ölçek geliştirmek amaçlanmıştır. Bu amaca yönelik olarak hazırlanan açık uçlu sorular yardımıyla çevrimiçi görüsşmeler gerçekleştirilmiştir. Elde edilen nitel veri ölçümlenebilir ölçek maddelerine dönüştürülmüş ve Sosyo-demografik Bilgi Formu, Genel İş Memnuniyeti, İșten Ayrılma Niyeti ölçekleriyle birlikte farklı sektörlerde çalışan 150 katılımcıya (Erkek: 78, Kadın: 72; Yaş: 22 - 67, Ort:38.3, SS:12.43) uygulanmıştır. Elde edilen bulgular ölçeğin 'Yöneticiye Güven', 'Kuruma Güven' ve 'Çalışana Güven' olmak üzere üç faktörlü bir yapı gösterdiğini ortaya koymuştur. Kriter geçerliliği kapsamında gerçekleştirilen korelasyon analizi sonuçları ölçeğe ait tüm alt boyutların Genel İş Memnuniyeti ve İşten Ayrılma Niyeti ile ilişkilendiğini göstermektedir. Ayırt etme geçerliliğini test etmek amacıyla gerçekleştirilen analizler işin sağlık açısından tehlike algısının az tehlikeli ve çok tehlikeli olduğu gruplarda Örgüte Güven ve Çalışana Güven boyutlarında anlamlı farklılık olduğunu göstermiştir. Sonuç olarak, bu çalışmada elde edilen bulgular COVID - 19 Hazırlılığı Örgütsel Güven Ölçeği’nin Türk örnekleminde psikometrik özellikleri görgül olarak test edilmiş geçerli ve güvenilir bir ölçek olduğunu göstermektedir.

Anahtar Kelimeler: Örgütsel Güven, COVID - 19, COVID - 19 Hazırlılığı, Ölçek Geliştirme

\section{Giriş}

Ülkemizde COVID - 19 salgınıyla mücadele amacıyla devletin tüm kurumları eylem planları geliştirmiş ve uygulamaya almıştır. Daha küçük ölçekte iş örgütleri salgın sürecinde kayıplarını telafi etmek; örgütün ve işlerin salgın sonrasında da devamlılığını sağlamak amaciyla eylemlerde bulunmaktadır. Diğer taraftan, salgın bireylerin günlük yaşam faaliyetlerini kısıtlamış, psikolojik ve ekonomik olarak olumsuz etkilemiş görünmektedir. Salgınla mücadelede hem bireysel düzeyde hem kurumsal düzeyde (iş örgütleri devlet kurumları) farklı ve birbirini tamamlayıcı görev ve sorumluluklar ortaya çıkmıştır. Bireylerin kendilerini ve çevrelerini korumak için almaları gereken önlemler ve kurallar belirlenmiştir.

Sosyal sermayenin bir türü olan sosyal güvenin (Coleman, 1988; Fukuyama, 1988), sosyal aktörler arasındaki sosyopolitik işbirliğini kolaylaştırdığı ve bu işbirliğinin gelişmesine katkı sağladığı birçok çalışmada ortaya konulmuştur (Coleman, 1988; Putnam, 2000). Yapılan araştırmalar, sosyal güvenin bilgi paylaşımını arttırdığını, ilişkileri geliştirdiğini, çatışma ve problem çözme becerilerini geliştirdiğini, karşılıklı kabul ve açıklığ desteklediğini göstermektedir (Six, 2008). Elde edilen bulgular, yüksek güvene sahip bireylerin gönüllülük faaliyetlerine daha fazla katıldıklarını (Stolle, 2001), toplumun daha aktif üyeleri olduklarını ve daha sağlam ilişkiler kurduklarını göstermektedir (Delhey and Newton, 2003; Newton, Stolle ve Zmerli, 2018). Bu faydalar açısından, toplumlar tarih boyunca ekonomik veya kurumsal sıkıntılar gibi global zorluklar karşısında bireylerin birbirlerine ve kurumlara güvenmelerini sağlamaya çalışmışlardır (Kennedy, Kawachi ve Brainerd, 1998).

Newton vd. (2018)'e göre sosyal güven; sosyal bağlllık, uyum ve sosyal kararlılık için önemli faktörlerden biri olarak değerlendirilirken, Uslaner (2002) ve Delhey (2014) tarafindan ise sosyal güven; işbirlikçi, prososyal ve alturistik davranış ile ilişkilendirilmektedir. Stolle (2001)'ye göre yüksek güvene sahip bireyler düşük olanlara göre diğerleriyle daha fazla etkileşime odaklanmaktadır. Siegrist, Gutscher ve Earle (2005) tarafından İsviçre'de yapılan araştırmada, otoriteye ve liderlere karşı yüksek güvene sahip bireylerin teknolojik, sosyal ve doğal tehlikelere karşı risk algılarının daha düşük olduğu bulunmuştur. Benzer şekilde, Su, Li ve Zhang (2019) tarafından gerçekleştirilen çalışmada sosyal güveni yüksek bölgelerdeki örgütsel karar vericilerin daha fazla riski kabul ettikleri ve riskli önerileri daha fazla onayladıkları bulunmuştur. Güvenin yüksek olduğu gruplarda riskli durumlar karşısında bireyler riskin büyümesini engellemek amacıyla davranışlarını kontrol etmektedirler. Bu tür gruplarda bireyler ortak hedef yönelimli olarak hareket ederek, bu hedefe ulaşmak amaciyla yüksek sorumluluk gösterirler (Schiefer ve Van der Noll, 2017). Bu yönelim pandemiyle geniş ölçekte ve uzun dönem mücadele amaciyla bireyler arasında iş birliğinin oluşturulmasında önemlidir (Van Bavel JJ. vd., 2020). Pandemi döneminde, bu sonuçları destekleyecek şekilde, Kuzey Kore ve Singapur'da gerçekleştirilen vaka analizinde sosyal güvenin COVID - 19 salgının yayılımının azalmasına ve kontrol altına alınmasına katk1 sağladığı bulunmuştur (Kye ve Hwang, 2020). Sosyal güven yalnızca bireyin sosyal hayatında değil, iş hayatında da önemli bir kavramdır. Katz ve Kahn (1966), örgütleri sosyal sistemler olarak tanımlamaktadır. Örgütsel güven bağlamında değerlendirildiğinde, bireylerin işyerinde olumlu ilişkiler geliştirme ve sürdürmelerinin ve işe adaptasyonlarının, örgütün yarattığı sosyal güven iklimi ve kişinin sahip olduğu sosyal güvenin karşılıklı etkileşiminin bir sonucu olarak ortaya çıtığ değerlendirilmektedir (Mamatoğlu, 2020). Örgütsel güven, sosyal güvenin özel bir hali olarak örgütlerde; işbirlikçi davranma, takım ruhu geliştirme, amaç oluşturma (McAllister, 1995; Jones ve George, 1998; Mayer vd., 1995) ve bağlılığın artması gibi örgütsel süreçlere katk1 sunmaktadır (Huff ve Kelley, 2003). Bu çıktılar düşünüldüğünde, iş yerinde yeni iş yapış şekilleri ve motivasyon kaynakları ortaya çıkaran COVID - 19 salgınına (Mamatoğlu ve Aksoy, 2021) örgütlerin hazırlılıklarına karşı çalışanların ne ölçüde güvendiklerinin ve bu güvenin nasıl şekillendiğinin ölçümlenmesi önemlidir. 
Bu çalışmada, Türkiye'de -19 salgını ilan edildikten sonra; makro düzeyde devletin, daha aşağıda örgütlerin, çalışanların ve örgüt yöneticilerinin, salgınla ilgili olarak aldığ 1 kararlar, tedbirler, çalışanların kendi aralarında ve örgütle kurduğu iletişim, iş yapma tarzı ile ilgili getirilen yenilikler bağlamında çalışan ve örgüt arasında kurulan güven-güvensizliğin nasıl yapılandığını ölçümlemeye yönelik bir ölçek geliştirmek amaçlanmaktadır.

\section{Sosyal Güven}

Güven kavramı yalnızca psikolojinin değil, sosyoloji, antropoloji, politik bilim, tarih, ekonomi ve yönetim gibi farklı disiplinlerin araştırma konusu olmuştur (Lewicki ve Bunker, 1996; Gambetta, 1988; Worchel, 1979). Farklı disiplinlerin güven konusunda araştırmalar gerçekleştirmeleri, güven kavramının tanımlanmasını zorlaştırsa da, ilk tanımlamalar bireyin diğerlerinin motivasyonlarına ve niyetlerine güveniyle ilişkilendirilmektedir (Lewicki, McAllister ve Bies, 1998; Deutsch, 1958; Mellinger, 1956; Read, 1962). Bu tanımlamalara karşılık, davranış odaklı gerçekleştirilen tanımlamalar güveni; güvenilen kişinin güvenen birey üzerinde oluşturduğu olumlu beklentiler olarak değerlendirmektedir (Barber, 1983; Hosmer, 1995; Read, 1962). Ancak bahsedilen tanımlamalar güvenin inşa edilmesi sürecini ve altında yatan mekanizmaları açıklamada yetersiz kalmaktadır (Mamatoğlu, 2020). Mamatoğlu (2020), güven kuramlarını sosyo-psikolojik kuramlar, sosyo-demografik kuramlar, yaşam deneyimleri kuramları ve ideolojik kuramlar şeklinde alt başlıkları olan bireysel kuramlar ve ăg kuramlarl ve ülke düzeyi gösterge kuramları alt başlıklarıyla toplumsal kuramlar olarak iki genel başlıkta incelenebileceğini ifade etmektedir. Mamatoğlu (2020), güven ya da güvensizliğin söz konusu tüm düzeyler arasında geçiş ve etkileşimlerine işaret etmektedir. Bu bağlamda sosyal güven birey, yakın çevresi, toplum, toplumsal kurumlar ve devlet arasında karşılıklı olarak ortaya çıar. Öyle ki; COVID-19 krizini yaşayan birey, içinde bulunduğu sosyal çevre ve kurumlara; onların verdiği güven kadar güvenebilir (Özkılıçcı ve Mamatoğlu, 2021). Özkılıçcı ve Mamatoğlu (2021), COVID-19'a ait algilar ve tutumların siyasi lider tercihleri üzerindeki yordayıcılığını inceledikleri çalışmalarında, koronavirüs salgınıyla baş etmede kişilerin kendilerine ve diğerlerine güven algılarını üç boyutlu bir ölçek üzerinden değerlendirmişlerdir. Ölçeğin geleceğe güven olarak isimlendirilen ilk boyutu yakın gelecekte salgının son bulması için tedavi yöntemlerinin geliştirileceğine ilişkin güveni; kişisel güven olarak isimlendirilen ikinci boyutu salgından kişisel önlemler alınarak çözüme sunulacak katkıya güveni ve son olarak diğerlerine güven olarak isimlendirilen hastalığın son bulması için diğer kişilerin, kurumların ve küresel aktörlerin alacağ 1 önlemlere duyulan güveni içermektedir. Söz konusu çalışma (Özkılıçcı ve Mamatoğlu, 2021) virüsle baş etmede alınan kişisel tedbirlere güvenin düşük olduğu kişilerin daha çok bu dönemde kendileri yerine karar alacak, söylemleri ile umut verecek karizmatik liderlere yöneldiklerini göstermiştir. Bu çalışmada ise koronavirüsle baş etmede genel olarak sosyal güvenden ziyade çalışan kesimin bağlı bulunduğu örgüte kurum olarak, örgüt liderlerine ve diğer çalışanlara salgınla ilgili alınan tedbirlere güvenlerini değerlendiren bir ölçek çalışmasına yer verilecektir. Bu bağlamda, toplu halde bir arada çalışılan işyerlerinde çalışanın işe devamı, motivasyonu ve üretkenliği üzerinde; salgın döneminde alınan tedbirlerin çalışanlar tarafindan nasıl değerlendirildiğinin önemli olduğu düşünülmektedir. Söz konusu ölçek çalışmasının ilgili alana katkı sağlayacağına inanılmaktadır.

\section{Örgütsel Güven}

Salgın hastalıklar veya doğal afetler gibi önemli olumsuz gelişmeler hizmetlerin sürekliliğini aksatması bakımından örgütler için krizler yaratabilmektedir (Morgeson, Mitchell ve Liu, 2015). Bu tür süreçlerde çalışanlar kriz durumlarında nasıl hareket edeceklerine genel olarak sosyal normlara bakarak karar vermektedirler (Cialdini vd.., 1991; Harvey veHaines, 2005). Çalışanların sosyal normlar ile ilgili algısı diğerlerinin ne yaptığı, neyi onayladıkları ve onaylamadıkları temelinde şekillenmektedir (Cialdini., 1991). Diğer taraftan, yönetimin kriz sürecini ve sosyal normları nasıl yönettiği çalışanların örgütsel güven (Koronis Ponis, 2018) gibi örgüte yönelik tutumlarını (Bundy., 2017; Harvey Haines, 2005) etkilemektedir. Güven özellikle belirsizlik ve muğlaklık dönemlerinde daha önemli hale gelmektedir (Gustafsson 2020). Örgütsel güven; örgütte işten ayrılma niyeti, örgütsel bağlılık, örgütsel vatandaşlık, çalışan sinizmi ve iş memnuniyetinin öncülü olarak önemli rol oynamaktadır (Archimi vd., 2018; Dirks and Ferrin, 2002; Hough vd., 2015; Tourigny., 2019). Yapılan araştırmalar örgütsel güven arttıkça örgütsel bağlılık (Diffie-Couch, 1984; Fairholm, 1994; Fink, 1993; O Reilly, 1994, Pillai vd., 1999;; Sonnenburg, 1994; Aktaran: Demircan ve Ceylan, 2003) ve örgütsel vatandaşlığın (Pillaivd., 1999; Konovsky ve Pugh, 1994; Marlowe ve Nyhan, 1992; Aktaran: Demircan ve Ceylan, 2003) arttığını, stresin (Bair ve Stamand, 1995; Sonnenburg, 1994, Aktaran: Demircan ve Ceylan, 2003) ise azaldığını göstermektedir.

Özetle güven, örgüt içinde çalışanların örgütsel bağlılığının artması, çalışanların performans hedeflerinin belirlenmesi ve örgütsel hedeflerin başarılması için anahtar bir gerekliliktir (Gilbert ve Li-Ping Tang, 1998). Güven seviyesi arttıkça risk alma konusunda daha iyi bir pozisyon yakalamak, örgüt kaynaklarını etkili bir şekilde kullanmak mümkün olduğu gibi güven örgüte ait tüm etkinliklerin gerçekleşmesinde kolaylaştırıcı bir rol oynar (Yilmaz ve Atalay, 2009). Bu bağlamda bu çalışmada gerçekleştirilecek örgütsel güven ölçeğinin çeşitli örgütsel değişkenler ile ilişkisine bakmak ölçeğin kriter geçerliğinin test edilmesine katkı sağlayacaktır. Örgütsel güven ile işten ayrılma niyeti ve iş memnuniyeti bu amaçla bu çalışmada kullanılan iki değişken olacaktır. Güven konusu işten ayrılma niyetinin yordayıcısı olarak tanımlandığında duygusal (McAllister, 1995) olduğu kadar sosyo- bilişsel (Cruise ve McLeary 2018) bir içerik taşır. Bir başka deyişle örgütsel güven bir manada işverene güven ve destek duygusudur, işverenin açık ve sözlü taahhütlerini yerine getireceği inancı iken bu inancın oluşmasında çalışan ilgili davranışlarını bunların getireceği yarar ve zararları bilinçli bir şekilde analiz etmektedir. Bu bağlamda örgütsel güven çalışanın gerçek veya algılanan örgütten ayrılma niyetiyle negatif yönde ilişkilidir (Al-Sakarnah ve Alhawary, 2009; Haibo, Liluo, Wenquan ve Xiaoming, 2007). Bu çalışmada sosyal güven ve işten ayrılma niyeti arasında negatif yönde bir ilişki beklenmektedir. Öte yandan; örgütsel güven ve iş memnuniyeti arasındaki ilişki pek çok çalışmada ortaya konulmuştur (örneğin; Driscoll, 1978; Shockley Zalabak, Ellis, Winograd, 2000). Bir kısım görüş çalışanın yaşadığı memnuniyet verici iş deneyimlerinin bir süre sonra güven 
oluşumuna katkıda bulunduğunu ifade ederken (Horppu Kuivalainen, Tarkiainen, Ellonen, 2008; Moliner, Sanchez, Rodriguez, Callarisa, 2007). Bir diğer görüş açısı örgütsel düzenlemelerin çalışanda "örgütüm beni destekleyip koruyor işim güvence altında" fikri veren güven ortamının iş memnuniyetine neden olduğunu (Chiou vePan, 2009; Liu, Siu ve Shi, 2010) ifade etmektedir. Böylece bu çalışmada, örgütsel güven ile iş memnuniyeti arasında pozitif yönde bir ilişki beklenmektedir.

\section{Pandemi Döneminde COVID - 19 Hazırlılığı Örgütsel Güven}

COVID-19 salgınıyla birlikte, örgütler hazırlılıklarını arttırmak amacıyla, çalışanları uzaktan çalışma yönlendirmişler veya bazı işverenler mücbir sebeplerle işletmelerini geçici süreliğine/sürekli kapatmak zorunda kalmışlardır. Ancak, yakın zamanda gerçekleştirilen çalışmalar uzaktan çalışmanın her örgüt için uygun olmadığını, bunun yapılan işin niteliği ve örgütün uzaktan çalışmaya sağladığı imkanlara göre değişkenlik gösterebileceğini ortaya koymaktadır (Hatayama vd., 2020). Gerçekten de, hizmet sektörünün büyük bölümünü evden çalışmaya yönlendirebilirken, ağırlıklı olarak inşaat, imalat, tarım ve turizm gibi sektörler bunu gerçekleştirmesi pek de mümkün olamamaktadır (ILO 2020). Her ne kadar pandemiden dolayı çalışanların işten uzak kalması gerekse de, bu durum çalışanların işyerinde bulunma gerekliliğini ortaya çıkarmaktadır. Ek olarak, bulgular birtakım çalışanların COVID - 19 salgınına rağmen işten atılma korkusu, kendini işverene gösterme, ev sorunlarından kaçma, iş bağımlılı̆̆ı gibi motivasyonlarla işyerinde bulunduklarını göstermektedir (Mamatoğlu ve Aksoy, 2021). Ayrıca, normalleşme adımlarıyla birlikte örgütler çalışanlarını işyerlerine geri çağırmaya başlamışlardır. Ancak, Aksoy ve Mamatoğlu (2020) gerçekleştirdikleri çalışmada, bulaşma riskinin yarattığ 1 olumsuzluklar nedeniyle çalışanların işten uzaklaştıkları işe gitmeme eğilimi taşıdıkları görülmüş̧ür. Diğer taraftan, bu dönemde salgın riskine karşı sağlık otoriteleri tarafindan örgütlerde denetimler arttırılarak, uygunsuzluk görülen işletmeler veya işletmelerin ilgili bölümlerinde üretim veya hizmet durdurulmaktadır. Belirtilen sebepler ve örgütsel güvenin örgüte katkıları değerlendirildiğinde, örgütlerin COVID - 19 salgınına yönelik hazırlılıkları ve bu hazırlıklara çalışanın ne kadar güvendiği daha önemli gelmektedir.

\section{Yöntem}

\section{Örneklem}

Araştırmanın nitel araştırma fazında farklı sektörlerden 9 çalışanla uzaktan ve telekonferans yöntemiyle görüşmeler gerçekleştirilmiştir. Ölçeğin faktör yapısı, iç güvenirliği, kriter geçerliliği ve ayırt etme geçerliği 150 kişilik örneklem üzerinden incelenmiştir. Katılımcılardan kolayda örnekleme yöntemi ile veri toplanmıştır. Katılımcılar 22-67 yaş aralığında (Ort. = $38.3 S S=12.43$ ), 78'i erkek 72'si kadın, \%62'si büyükşehirde yaşayan, $\% 58$ 'i evli, \%49'u 2500-5000 TL aras1 bireysel gelire sahip, \%59'u lisans mezunu, \%57'si özel sektör çalışanıdır.

çalışma saati eklenmesi, yarı zamanlı çalışma, işyerinin kapanması, işine son verilmesi) karşılaştırılmasıyla gerçekleştirilmiştir. $\mathrm{Bu}$ karşılaştırmalardan yalnızca

\section{Araçlar}

\section{Demografik Bilgi Formu}

Demografik bilgi formu yaş, cinsiyet, yaşanılan yer, medeni durum, gelir düzeyi, eğitim durumu, çalışılan sektör ve işin sağlık açısından tehlike durumu değişkenlerinden oluşmaktadır.

\section{İşten Ayrılma Niyeti}

Katılımcıların işten ayrılma niyetlerini ölçmek amacıyla 'Çalıştığınız kuruluştan ayrılmak istiyor musunuz?' sorusu sorulacak ve 6'll likert tipi (1=Kesinlikle Uygun Değil, 6=Kesinlikle Uygun) ölçek ile derecelendirilecektir.

\section{Genel İş Memnuniyeti}

Katılımcıların genel memnuniyet düzeylerini ölçmek amacıyla 'Genel olarak, işinizden / çalıştığınız kuruluştan ne kadar memnunsunuz?' sorusu sorulacak ve 6'lı likert tipi (1=Hiç Memnun Değilim, 6=Çok Memnunum) ölçek ile derecelendirilecektir.

\section{COVID - 19 Hazırııı̆̆ı Örgütsel Güven Ölçeği}

Çalışma kapsamında geliştirilen ölçek çalışanların, çalıştıkları organizasyonların COVID-19 salgınına hazırlılıklarına güvenini ölçmek amacıyla hazırlanmış 13 maddeden oluşmaktadır. Ölçek maddelerine 'Üstlerim Kovid-19 riski konusunda bilinçlidir', ‘İşyerimde çalışanlar Kovid-19 riski ile mücadelede ortak sorumluluk bilinciyle hareket eder', 'Çalıştığım kurumun önceliği üretimden önce çalışanlarını Kovid-19 riskine karşı korumaktır' örnek olarak verilebilir. Ölçek 6 aralıklı (1=Kesinlikle Katılmıyorum, 6=Kesinlikle Kat1lıyorum) Likert tipi şeklinde derecelendirilmiştir. Ölçeğin faktör yapısı geçerlilik ve güvenirlik analizi sonucu elde edilen psikometrik özellikleri bulgular bölümünde verilmiştir.

\section{İşlem}

Ölçek çalışması kapsamında COVID $\quad-19$ salgını başladıktan sonra mümkün olan tüm kaynaklar aracılığıyla (yazılı, görsel basın, birebir telekonferans görüşmeleri, bireysel deneyimler, yakın çevre deneyimleri vb.) sürecin çalışanlar üzerindeki etkileri gözlemlenmiştir. Araştırma kapsamında öncelikle 9 çalışan ile nitel görüşmeler gerçekleştirilmiştir. Nitel görüşmelerde elde edilen veri, iki araştırmacının ortak bulguları ve fikir birliği sonucunda sonraki aşamada ölçülebilir ölçek maddelerine dönüştürülmüştür. Ölçülebilir hale getirilen maddeler uygulama öncesinde bir çalışana okutulmuş ve maddelerin anlaşılabilirliği değerlendirilmiştir. Uygulama aşamasında ölçeğin kriter geçerliğini değerlendirmek amacıyla, geliştirilen ölçekle birlikte genel iş memnuniyeti ve işten ayrılma niyeti ölçekleri uygulanmıştır. Ölçeğin ayırt etme geçerliği ise sağlık açısından algılanan tehlike gruplarının (az tehlikeli, tehlikeli, çok tehlikeli) ve salgın sonrasındaki çalışma düzenindeki farklılıklar (Uzaktan çalışma, tam zamanlı vardiyalı/dönüşümlü çalışma, ücretsiz izne çıkarılma, çalışma saatlerinin düşürülerek vardiya/nöbet sistemine geçilmesi, esnek çalışma, salgın nedeniyle artı

anlamlı sonuç elde edilen sağlık açısından işin tehlike algıs1 gruplarının karşılaştırma sonuçları bulgular ve tartışma bölümünde verilmiştir. Çalışmaya katılmayı kabul 
eden tüm katılımcılardan bilgilendirilmiş onam alınmıștır. $\mathrm{Bu}$ çalışmanın gerçekleştirile bilmesi için Bolu Abant İzzet Baysal Üniversitesi İnsan Araștırmaları Etik Kurulundan (26.05.2020 / Protokol No: 2020/137) ve Sağlık Bakanlığından onay alınmıştır.

\section{Bulgular}

\section{COVID - 19 Hazırlılığı Örgütsel Güven Ölçeği Faktör Yapısı}

Tablo 1.

COVID - 19 Hazırlılı̆̆g Örgütsel Güven Ölçeği'ne ait Faktör Analizi Sonuçları

\begin{tabular}{|c|c|c|c|}
\hline & Faktör 1 & Faktör 2 & Faktör 3 \\
\hline \multicolumn{4}{|l|}{ Yöneticiye Güven } \\
\hline 1.Üstlerim Kovid-19 riski konusunda bilinçlidir. & .91 & & \\
\hline 2.Üstlerim Kovid-19 riskine karşı çalışanlarla sürekli iletişim halindedir. & .80 & & \\
\hline 3.Üstlerim Kovid-19 riskine karşı güvenliği sağlamada yetkindirler. & .71 & & \\
\hline 4.Üstlerim her çalışanın diğer çalışana Kovid-19 bulaştırabileceğinin farkındadır. & .73 & & \\
\hline \multicolumn{4}{|l|}{ Kuruma Güven } \\
\hline 5.Çalıştığım kurumun önceliği üretimden önce çalışanlarını Kovid-19 riskine karşı korumaktır. & & .53 & \\
\hline 6.Çalıştığım kurumda Kovid-19'a karşı alınan önlemler yeterlidir. & & .90 & \\
\hline 7.Çalıştığım kurumun Kovid-19’a karşı nasıl hareket edilmesi konusunda bir yol haritası vardır. & & .74 & \\
\hline 8.Çalıştığım kurum Kovid-19'a karşı gerekli önlemlerin alınması konusunda erken davranmıştır. & & .79 & \\
\hline \multicolumn{4}{|l|}{ Çalışana Güven } \\
\hline 9.İşyerimde çalışanlar Kovid-19 riskine karşı işyerinde gerekli kişisel tedbirleri alır. & & & .46 \\
\hline 10.İ̧syerimde çalışanlar Kovid-19 riski ile mücadelede ortak sorumluluk bilinciyle hareket eder. & & & .68 \\
\hline $\begin{array}{l}\text { 11.İ̧yerimde çalışanlar bir diğerine Kovid-19 bulaştırma ihtimaline karşı gerekli hassasiyeti } \\
\text { gösterir. }\end{array}$ & & & .98 \\
\hline 12.İşyerimde çalışanlar diğer çalışanları Kovid-19'a karşı önlem alması konusunda uyarırlar. & & & .86 \\
\hline
\end{tabular}

Ölçeğin üç faktörlü yapısı incelenmiş ve alt boyutlar “Yöneticiye Güven' '(1., 2., 3. ve 4. maddeler), “Kuruma Güven"' (5., 6., 7. ve 8. maddeler), “Çalışana Güven' (9., 10., 11. ve 12. maddeler) şeklinde isimlendirilmiştir. Buna göre, ölçek alt boyutlarından çalışana güven; işyerinde COVID -19 tedbirleri anlamında çalışanların hem kendilerini hem diğerlerini korumaya yönelik olarak alacakları ya da aldıkları tedbirlere, bu konuda ortak mücadele ruhuna ne denli güven duyulduğunu değerlendirmektedir. Yöneticiye güven, COVID-19 konusunda yöneticilerin farkındalığına, çalışanla kurduğu iletişime ve aldığ tedbirlere duyulan güveni değerlendirmektedir. Kuruma güven, COVID-19 konusunda örgütün çalışanları korumaya yönelik aldığ tedbirlere, izlediği yola ve planlamasına duyulan güveni değerlendirmektedir. Ölçeğin alt boyutlarından 'Yöneticiye Güven' kümülatif olarak toplam varyansın \%70'ini açıklarken, "Kuruma Güven" alt boyutunun kümülatif olarak toplam varyansın \%77'sini ve "Çalışanlara Güven" alt boyutunun kümülatif olarak toplam varyansın \%81'ini açıkladığı görülmüştür. Ölçek maddeleri ve faktör yükleri Tablo 1'de verilmiştir. Faktör analizi sonucunda faktör yükü .30'un altında olan üç madde analizlerden çıkarılmış ve ölçeğe 12 madde ile son hali verilmiştir. Ortaya çıkarılan üç faktörlü yapının doğrulayıcı faktör analizi ile model uyumu test edilmiştir. Elde edilen sonuçlar üç faktörlü yapıya ait model uyum indekslerinin iyi düzeyde olduğunu göstermiştir $(\chi 2=139$, $\mathrm{df}=51, \chi 2 / \mathrm{df}=2,72, p<.001, \mathrm{RMSEA}=.079, \mathrm{SRMR}=$
Çalışanların örgütlerine COVID - 19 hazırlılığı konusunda güvenlerinin alt boyutlarını ortaya belirlemek amaciyla hazırlanan on beş maddeden oluşan ölçeğe faktör analizi yapılmıştır. Maximum Likelihood Direct Oblimin rotasyonu ve faktörlerin üçe sabitlenmesi sonucunda ölçeğin özdeğeri 1'in üzerinde üç faktör altında toplandığ1 ve bu faktörlerin toplam varyansın 81 'ini açıkladığı ortaya çıkmıştır. Ölçeğe ait Barlet Spherecity değerinin anlamlı $(p=.00<.05)$ ve KMO değerinin $(.95)$ yüksek olduğu görülmüştür. Ölçeğe ait faktör yükleri ise .46 ile .98 arasında değişmektedir (Tablo 1).
.076, NFI: .957, RFI: .945, IFI: .973, TLI: .964, CFI: .972, PGFI $=.601$, PNFI $=.740)$.

Alanyazında yer alan örgütsel güven ölçekleri genel olarak; örgüte, yöneticiye ve çalışma arkadaşlarına güven olmak üzere üç alt boyutta (Ellonen vd., 2008; Özkıllıçc1 ve Mamatoğlu; 2021; Tokgöz ve Seymen, 2013) ele alındığı gibi, örgüte güven ve yöneticiye güven şeklinde iki alt boyutta da ele alınmaktadır (Nyhan ve Marlowe, 1997; Demircan, 2003). Bu çalışmada da üç boyutlu bir yap1 ortaya konulmuştur. Bu ölçeğin diğerlerinden fark1 sadece genel olarak örgütsel güveni ve alt boyutlarını değil; COVID - 19 ile ilgili olarak diğer çalışanların hem kendilerini hem diğerlerini korumaya yönelik aldıkları tedbirlere, örgüt yöneticilerine ve genel olarak örgütün izlediği yola ve ileriye dönük korunma planlamasına duyulan güveni değerlendirmesidir.

\section{COVID - 19 Hazırlılığı Örgütsel Güven Ölçeği İç Güvenirliği}

COVID - 19 Hazırlılığı Örgütsel Güven Ölçeği’nin iç güvenirliğini test etmek amaciyla Cronbach's Alpha katsayısı hesaplanmıştır. Toplam ölçeğe ait Cronbach's Alpha değeri .96 iken; Yöneticiye Güven alt boyutunun Cronbach's Alpha değeri .90, Kuruma Güven alt boyutunun Cronbach's Alpha değeri .92, Çalışanlara Güven alt boyutuna ait Cronbach's Alpha değeri .93 olarak bulunmuştur.

Tablo 2. 
COVID - 19 Hazırlılığı Örgütsel Güven Ölçeği’ne Ait Güvenirlik Analizi Bulguları

\begin{tabular}{llllll}
\hline Maddde no & $\begin{array}{l}\text { Düzeltilmiş } \\
\text { Toplam Korelasyonu }\end{array}$ & $\begin{array}{c}\text { Madde } \\
\text { Madde } \begin{array}{c}\text { Silinirse } \\
\text { Crobach's Alpha }\end{array}\end{array}$ & $\begin{array}{l}\text { Maddde } \\
\text { (Devamı) }\end{array}$ & $\begin{array}{c}\text { No } \\
\text { Düzeltilmiş } \begin{array}{c}\text { Madde } \\
\text { Toplam Korelasyonu }\end{array}\end{array} \begin{array}{l}\text { Madde } \\
\text { Crobach's Alpha }\end{array}$ \\
\hline CHÖG1 & .77 & .96 & CHÖG9 & .79 & .94 \\
CHÖG2 & .77 & .96 & CHÖG10 & .82 & .95 \\
CHÖG3 & .83 & .95 & CHÖG11 & .78 & .75 \\
CHÖG4 & .77 & .94 & CHÖG12 & & .96 \\
CHÖG5 & .81 & .93 & & \\
CHÖG6 & .84 & .96 & & \\
CHÖG7 & .82 & .95 & & \\
CHÖG8 & .81 & &
\end{tabular}

Ölçeğe ait düzeltilmiş madde toplam korelasyonları .75 ile .84 aralığındadır. COVID - 19 Hazırlılığı Örgütsel Güven Ölçeği'ne ait ilgili maddelerin elenmesi halinde ortaya çıkan yeni Cronbach's Alpha değerleri ve düzeltilmiş madde toplam korelasyonları Tablo 2'de verilmiştir.

Yapılan analizler sonucunda, COVID - 19 Hazırlılı̆̆ Örgütsel Güven Ölçeği’nin alt boyutları ve toplam ölçek olarak iç güvenirliğinin yüksek olduğu söylenebilir.

\section{COVID - 19 Hazırlıı̆̆ı Örgütsel Güven Ölçeği Kriter Geçerliliği}

COVID - 19 Hazırlılı̆̆ Örgütsel Güven Ölçeği'nin kriter geçerliğini test etmek amaciyla toplam ölçek ve alt boyutları ile işten ayrılma niyeti ve genel iş memnuniyeti ölçekleri arasındaki ilişkiye Pearson korelasyon analizi ile bakılmıştır (Tablo 3). Korelasyon analizi sonucunda COVID - 19 Hazırlılığı Örgütsel Güven Ölçeği'nin toplam ölçek ve alt boyutları ile genel iş memnuniyeti ve işten ayrılma niyeti arasında ilişkiler bulunmuştur.

Tablo 3.

\begin{tabular}{|c|c|c|c|c|c|c|}
\hline & GIM & İAN & $\mathrm{YG}$ & $\mathrm{KG}$ & ÇG & ÖG \\
\hline$\overline{\text { GiM }}$ & 1 & & & & & \\
\hline İAN & $-.534^{* *}$ & 1 & & & & \\
\hline YG & $.484^{* *}$ & $-.298^{* *}$ & 1 & & & \\
\hline KG & $.526^{* *}$ & $-.338^{* *}$ & $.832^{* *}$ & 1 & & \\
\hline CG & $.517^{* *}$ & $-.336^{* *}$ & $.758^{* *}$ & $.785^{* *}$ & 1 & \\
\hline CHÖG & $.548^{* *}$ & $-.348^{* *}$ & $.933^{* *}$ & $.945^{* * *}$ & $.906^{* *}$ & 1 \\
\hline
\end{tabular}

GiM: Genel İş Memnuniyeti, İAN: İşten Ayrılma Niyeti, YG: Yöneticiye Güven, KG: Kuruma Güven, ÇG: Çalışanlara Güven, CHÖG:

COVID - 19 Hazırlılığı Örgütsel Güven Toplam Ölçek

COVID - 19 Hazırlılı̆ğ Örgütsel Güven Ölçeği ve alt boyutları ile genel iş memnuniyeti ve işten ayrılma niyeti arasındaki ilişkiler incelendiğinde; genel iş memnuniyeti ve yöneticiye güven alt boyutu $(\mathrm{r}=.484, p<.01)$, kuruma güven alt boyutu $(\mathrm{r}=.526, p<.01)$, çalışanlara güven alt boyutu $(\mathrm{r}=.517, p<.01)$ ve toplam ölçek $(\mathrm{r}=.548, p<$ $.01)$ arasında pozitif yönde anlamlı ilişkinin olduğu görülmüştür. İşten ayrılma niyetinin yöneticiye güven alt boyutu $(\mathrm{r}=-.298, p<.01)$, kuruma güven alt boyutu $(\mathrm{r}=$ $.338, p<.01)$, çalışanlara güven alt boyutu $(\mathrm{r}=-.336, p<$ $.01)$ ve toplam ölçek $(r=-.348, p<.01)$ ile negatif yönde anlamlı ilişkilendiği görülmüştür. Gerçekleştirilen analizler sonucunda COVID - 19 Hazırlılığı Örgütsel Güven ölçeğinin; yöneticiye güven, kuruma güven ve çalışanlara güven alt boyutlarının tümünün genel iş memnuniyeti ile pozitif ve işten ayrılma niyeti ile negatif ilişkilendiği görülmüştür. Elde edilen bulgular, belirsizlik ve muğlaklığın yoğun olduğu pandemi döneminde örgütün çalışanların sağlığını düşündüğ̈nü tahhüt etmesinin ve gerekli önlemleri almasının, çalışanların memnuniyetini arttırdığını ve işten ayrılma niyetinden uzaklaştırdığına işaret etmektedir. Yine bulgular, örgütsel taahhütleri uygulamakla yetkili kişi olan yöneticilerin de, çalışanların COVID - 19 salgınına karşı çalışanların aynı amaçlar doğrultusunda ve şeffaflıkla hareket ederek, gerekli alt yapı ve çalışanlar arasında uyumun sağlamalarının yine çalışanların memnuniyetini artırdığı ve işten ayrılma niyetini düşürdüğü şeklinde yorumlanabilir. Çalışana güven alt boyutu virüsün bulaşabilirliği açısından değerlendirildiğinde, çalışan; diğer çalışma arkadaşlarının COVID - 19 riski karşısında aldıkları tedbirlerin aynı zamanda iş arkadaşlarını koruma anlamı taşıdığını kavramaktadır denilebilir. Bu olumlu algının da çalışana güven alt boyutunun iş memnuniyetiyle olumlu ve işten ayrılma niyetiyle negatif yönde ilişkilenmesine neden olduğu söylenebilir.

Örgütsel güvenin duygusal (McAllister, 1995) olduğu kadar sosyo- bilişsel (Cruise ve McLeary 2018) bileşenleri düşünüldüğünde; COVID -19 konusunda işyerinde alınan tedbirlerle ilgili olarak işverenin açı ve sözlü taahhütleriyle ilgili olarak çalışanların bir bütün halinde; örgüt/kurum, örgüt yöneticileri ve diğer çalışanların tutumlarını bilinçli bir şekilde analiz ettiği, bu analizler sonucu alınan tedbirlerin kendisine verilen değerin bir sonucu olduğunu düşündüğü, duygusal olarak hissettiği iyilik halinin işinden doyumuna yol açtığı söylenebilir. Salgın döneminde çalışanın yaşadığı memnuniyet verici işyeri deneyimlerinin bir süre sonra alan yazının işaret ettiği gibi (Horppu Kuivalainen, Tarkiainen, Ellonen, 2008; Moliner, Sanchez, Rodriguez, Callarisa 2007) güven oluşumuna katkıda bulunduğu söylenebilir. Salgın döneminde iş güvencesinin zayıfladığ 1 bilinen bir gerçektir. Ancak COVID - 19 hazırlığını eksik yaparak çalışanların işyerinde güvenle çalışması için ideal koşulları 
yaratan örgüt; çalışanların hem sağlığını hem işini güvence altına almaktadır. Örgütün çalışanı destekleyip koruması işini güvence altına alması örgütsel güven ve iş memnuniyeti arasındaki pozitif ilişkiyi (Chiou and Pan, 2009; Liu, Siu, Shi, 2010) güçlendirmektedir denilebilir. Öte yandan söz konusu analizlerin doğal bir sonucu olarak çalışanın; Covid-19 riski karşısında kollandığı, çalışması için ideal şartların hazırlandığı üstelik bu çetrefil dönemde işyerinde çalışmaya devam ederek işten atılma riskinin bertaraf edildiği koşulları yaratan örgütünde kalma istediği artacaktır. Böylece COVID - 19 hazırlığı konusunda, kuruma, yönetici ve diğer çalışanlara duyulan güven çalışanın gerçek veya algılanan örgütten ayrılma niyetiyle ilgili alan yazının işaret ettiği gibi (Al-Sakarnah ve Alhawary, 2009; Haibo, Liluo, Wenquan ve Xiaoming, 2007) negatif yönde ilişkili olmaktadır denilebilir.

\section{COVID - 19 Hazırlılığı Örgütsel Güven Ölçeği Ayırt Etme Geçerliği}

COVID - 19 Hazırlılığı Örgütsel Güven Ölçeği alt boyutlarının işin sağlık açısından tehlikesi algısına göre farklılaşıp farklılaşmadığını test etmek amacıyla tek yönlü ANOVA analizi gerçekleştirilmiştir. Tek yönlü ANOVA analizi sonuçlarına göre Kuruma Güven $(\mathrm{F}(2,147)=8.08$, $p<.05)$, Çalışanlara Güven $(\mathrm{F}(2,147)=5.64, p<.05)$ alt boyutları ve COVID - 19 Hazırlılığı Örgütsel Güven ( F(2, $147)=6.14, p<.05)$ toplam ölçek puanı bakımından gruplar arasındaki fark anlamlıdır. Tek Yönlü Varyans analizi sonuçları Tablo 4'te verilmiştir.

Tablo 4.

İşin Sağlık Açısından Tehlike Algısına Göre COVID - 19 Hazırlılı̆̆ı Örgütsel Güven Ölçeği ve Alt Boyutlarında Farklılık Olup Olmadı̆̆ına Yönelik Gerçekleştirilen Tek Yönlü Varyans Analizi Sonuçları

\begin{tabular}{|c|c|c|c|c|c|c|c|}
\hline Değişken & $\begin{array}{lr}\text { İşin } & \text { Sağlık } \\
\text { Açısından } & \text { Tehlike } \\
\text { Algısı } & \\
\end{array}$ & $N$ & Ort & $S S$ & $F$ & $p$ & Anlamlı Fark \\
\hline Yöneticiye Güven & $\begin{array}{l}\text { 1.Az Tehlikeli } \\
\text { 2.Tehlikeli } \\
\text { 3.Çok Tehlikeli }\end{array}$ & $\begin{array}{l}59 \\
48 \\
43\end{array}$ & $\begin{array}{l}4.74 \\
4.45 \\
4.31\end{array}$ & $\begin{array}{l}1.21 \\
1.18 \\
1.45\end{array}$ & 2.77 & .64 & Fark yok \\
\hline Kuruma Güven & $\begin{array}{l}\text { 1.Az Tehlikeli } \\
\text { 2.Tehlikeli } \\
\text { 3.Çok Tehlikeli }\end{array}$ & $\begin{array}{l}59 \\
48 \\
43\end{array}$ & $\begin{array}{l}4.67 \\
4.23 \\
3.88\end{array}$ & $\begin{array}{l}1.23 \\
1.21 \\
1.61\end{array}$ & 8.08 & .00 & $(1)-(3)$ \\
\hline Çalışanlara Güven & $\begin{array}{l}\text { 1.Az Tehlikeli } \\
\text { 2.Tehlikeli } \\
\text { 3.Çok Tehlikeli }\end{array}$ & $\begin{array}{l}59 \\
48 \\
43\end{array}$ & $\begin{array}{l}4.84 \\
4.52 \\
4.28\end{array}$ & $\begin{array}{l}1.03 \\
1.14 \\
1.33\end{array}$ & 5.64 & .00 & $(1)-(3)$ \\
\hline COVID - 19 Hazırlılığı Örgütsel Güven Toplam Ölçek & $\begin{array}{l}\text { 1.Az Tehlikeli } \\
\text { 2.Tehlikeli } \\
\text { 3.Çok Tehlikeli }\end{array}$ & $\begin{array}{l}59 \\
48 \\
43\end{array}$ & $\begin{array}{l}4.75 \\
4.40 \\
4.15\end{array}$ & $\begin{array}{l}1.06 \\
1.09 \\
1.38\end{array}$ & 6.14 & .00 & $(1)-(3)$ \\
\hline
\end{tabular}

COVID - 19 Hazırlılığı Örgütsel Güven ölçeği ve alt boyutlarının işin hangi düzeyindeki tehlike algısına göre anlamlı olarak farklılaştığını test etmek amacıyla Tukey testi kullanılmıştır. Kuruma Güven alt boyutunda, çok tehlikeli (Ort: 3.88) ve az tehlikeli (Ort= 4.67) gruplar arasında anlamlı fark olduğu görülmüştür. Çalışanlara güven alt boyutunda çok tehlikeli (Ort: 4.28) ve az tehlikeli $(O r t=4.84)$ gruplar arasında anlamlı farklılık gözlenmiştir. Son olarak COVID - 19 Hazırlılığ Örgütsel Güven toplam ölçeği için çok tehlikeli (Ort: 4.15) ve az tehlikeli $(O r t=4.75)$ gruplar arasında anlamlı fark bulunmuştur.

Elde edilen bulgular, sağlığı açısından çok tehlikeli işlerde çalıştı̆̆ algısına sahip çalışanların sağlık açısından az tehlikeli işlerde çalıştığı algısına sahip çalışanlara göre; diğer çalışanlara, kuruma ve genel olarak örgüte daha az güvendiklerine işaret etmektedir. Ancak yöneticiye güvenen çalışanın işini ne denli tehlikeli ya da tehlikesiz algılamasından bağımsız görünmektedir. Sağlık açısından yaptığ1 işin çok tehlikeli olduğunu düşünen çalışanlar; COVID - 19 salgınıla birlikte bu tehlikenin belki de katlandığını düşünmektedir.

Artan tehlike algısı ile birlikte, belki de çalışanlar sağlık riski konusunda hassaslaşmakta, örgütlerinden ve diğer çalışanlardan daha fazla önlem alınmasını ve dikkatli olunmasını beklemektedir. Belirsizliğin ve karmaşanın üst düzeyde olduğu pandemi döneminde, sağlık açısından artan tehlike özellikle yaptığ 1 iși daha tehlikeli olarak tanımlayan çalışanların işyerlerinde mevcut imkan ve kaynaklarla alınan tedbirleri yetersiz görmelerine ve işyerinde yöneticilerine, diğer çalışanlara, kuruma olan güvenlerini düşürmektedir denilebilir.

Bulgular, ilgili yakın dönem alanyazınla tutarlıdır. Örneğin; Bish \& Michie (2010) ve Chuang vd. (2015) pandemi dönemlerinde sağlık riskini önleyici davranışların sosyal güven ile ilişkili olduğunu bulmuşlardır. Benzer şekilde COVID - 19 pandemi dönemine özgü olarak Chambon vd. (2020) tarafindan gerçekleştirilen çalışmada ise; sağlık riskini önleyici davranışların otoriteye güven ile ilişkili olduğu ortaya konulmuştur.

\section{Sonuç}

Bu çalışmada, Türkiye'de Covid-19 salgını ilan edildikten sonra; makro düzeyde devletin, daha aşağıda örgütlerin, çalışanların ve örgüt yöneticilerinin, salgınla ilgili olarak aldığı kararlar, tedbirler, çalışanların kendi aralarında ve örgütle kurduğu iletişim, iş yapma tarzı ile ilgili getirilen yenilikler bağlamında çalışan ve örgüt arasında kurulan güven-güvensizliğin nasıl şekillendiğini değerlendirmeye yönelik bir ölçek geliştirmek amaçlanmıştır. Çalışmada, COVID - 19 Hazırlılığı Örgütsel Güven ölçeğinin yöneticiye güven, kuruma güven ve çalışana güven olmak 
üzere üç boyutlu bir yapısı olduğu ortaya konulmuştur. Yapılan analizler; COVID - 19 Hazırlılığı Örgütsel Güven Ölçeği'nin Türk örnekleminde psikometrik özellikleri görgül olarak test edilmiş geçerli ve güvenilir bir ölçek olduğunu göstermektedir.

Geliştirilen ölçek, özellikle pandemi döneminde işten ayrılmaların yoğun olarak yaşandığı sağlık çalışanlarının örgütsel COVID-19 hazırlılıklarına güvenlerinin değerlendirilebilmesine ve diğer değişkenlerle olan ilişkisinin ortaya konulabilmesine imkan sağlayabilecektir.

Elde edilen bulgular pandemi döneminde çalışanların memnuniyetleri için örgütlerin COVID - 19 hazırlılıklarını iyileştirmeyi ciddi şekilde gündeme almaları gerektiğini ortaya koymaktadır.

Özellikle sağlık açısından tehlikeli işlerin yapıldığı ya da en azından çalışanın algısında yapılan işin çok tehlikeli olduğu örgütlerde pandemi döneminde çalışanların güvenini kazanmanın önemli olduğu, çalışanlarda güven oluşturmak için örgütün ileri düzey stratejiler geliştirilmesi gerektiği söylenebilir.

\section{Beyannameler}

Etik Onay ve Katılma İzni

Calıșmaya katılmayı kabul eden tüm katılımcılardan bilgilendirilmiş onam alınmıştır. Bu çalışmanın gerçekleştirile bilmesi için Bolu Abant İzzet Baysal Üniversitesi İnsan Araştırmaları Etik Kurulundan (26.05.2020 / Protokol No: 2020/137) ve Sağlık Bakanlığından onay alınmıştır.

\section{Yayın İzni}

Uygulanamaz.

Veri ve Materyallerin Mevcudiyeti

Mevcut çalışma sırasında kullanılan ve/veya analiz edilen veri kümeleri, makul talep üzerine ilgili yazardan temin edilebilir.

Çıkar Çatışması

Yazarlar çıkar çatışması olmadığını beyan eder.

\section{Finansman}

Uygulanamaz.

\section{Yazar Katkıları}

N.M. verileri analiz etmiş ve yorumlamıştır. Ş.A. makalenin yazılmasında katkı sağlamıştır. Tüm yazarlar makalenin son halini okumuş ve onaylamıştır.

\section{Teșekkür}

Araştırmaya katılan tüm katılımcılara teşekkür ederiz.

\section{Kaynaklar}

Aksoy, Ş., \& Mamatoğlu, N. (2020). COVID-19 Salgın Döneminde Örgütlerde Güvenlik İkliminin İş Güvenliği Uzmanları Perspektifinden Değerlendirilmesi. Avrasya Sosyal ve Ekonomi Araștırmaları Dergisi, 7 (5), 26-37

Al-Sakarnah, B., \& Alhawary F. A (2009). Unraveling the relationship between employees' perception to organization and turnover intentions. Exploring the mediating effects of trust to organization. International Journal of Business and Management, 4 (10), 177-183.

Archimi, C.S., Reynaud, E., Yasin, H.M., Bhatti, Z.A., 2018. How perceived corporate social responsibility affects employee cynicism: The mediating role of organizational trust. J. Bus. Ethics, 151 (4), 907-921.

Barber, B. (1983). The Logic and Limits of Trust. New Brunswick, NJ: Rutgers University Press.

Bish, A., \& Michie, S. (2010). Demographic and attitudinal determinants of protective behaviours during a pandemic. A review. British journal of health psychology, 15(4), 797-824. https://doi.org/10.1348/135910710X485826

Bundy, J., Pfarrer, M.D., Short, C.E., Coombs, W.T., 2017. Crises and crisis management: integration, interpretation, and research development. J. Manage, 43 (6), 1661-1692.

Chambon, M., Dalege, J., Elberse, J., \& van Harreveld, F. (2020). A psychological network approach to attitudes and preventive behaviors during pandemics: A COVID-19 study in the United Kingdom and the Netherlands. https://doi.org/10.31234/osf.io/es45v

Chiou, J., \& Pan, L. (2009). Antecedents of internet retailing loyalty: differences between heavy versus light shoppers. Journal of Business and Psychology, 24 (3), 327-339.

Cialdini, R.B., Kallgren, C.A., Reno, R.R., (1991). A focus theory of normative conduct: A theoretical refinement and reevaluation of the role of norms in human behavior. In: Advances in Experimental Social Psychology, 24. Academic Press. 201-234.

Coleman JS. (1988). Social capital in the creation of human capital. American Journal of Sociology, 94, 95-120.

Cruise, P. A. ve McLeary C. (2018). The effect of socio-affective variables in the relationship between organizational trust and employee turnover intention. International Journal of Economics and Management Engineering, 12 (6), 816-822.

Delhey, J., and Newton, K. (2003). Who trusts? The origins of social trust in seven societies. Eur. Soc. 5, 93-137. doi: $10.1080 / 1461669032000072256$

Demircan, N., Ceylan, A . (2003). Örgütsel Güven Kavramı: Nedenleri ve Sonuçları. Yönetim ve Ekonomi. Celal Bavar Üniversitesi İktisadi ve İdari Bilimler Fakültesi Dergisi, 10 (2), $139-150$

Deutsch, M. (1958). Trust and suspicion. Journal of Conflict Resolution, 2, 265-279. doi: 10.1177/002200275800200401

Dirks, K.T., Ferrin, D.L., (2002). Trust in leadership: Metaanalytic findings and implications for research and practice. $J$. Appl. Psychol. 87 (4), 611-628.

Driscoll, J.W., (1978). Trust and participation in organizational decision making as predictors of satisfaction. Academy of Management Journal, 21 (1), 44-56.

Riikka Ellonen Kirsimarja Blomqvist Kaisu P., (2008). The role of trust in organisational innovativeness, European Journal of Innovation Management, 11 (2), 160-181.

Fukuyama F. (1995). Trust: the social virtues and the creation of prosperity. New York: The Free Press

Gambetta, D. (1988). Can We Trust, D.G. Gambetta (Der), Trust: Making and Breaking Cooperative Behaviors, 131-185, New York: Basil Blackwell.

Gilbert, J. and Li-Ping Tang, T. (1998). An examination of organizational trust antecedents, Public Personnel Management, 27 (3), 321-338

Gustafsson, S., Gillespie, N., Searle, R., Hope Hailey, V., Dietz, G., (2020). Preserving organizational trust during disruption. Organ. Stud., 0170840620912705

Haibo, Y., Liluo, F., Wenquan, L., \& Xiaoming, Z. (2007). Effects of organizational trust on individual attitudes, turnover intentions and organizational financial performance of Chinese companies. Acta Psychologica Sinica, 39 (2), 311-320. 
Harvey, S., Haines III, V.Y. (2005). Employer treatment of employees during a community crisis: the role of procedural and distributive justice. J. Bus. Psychol. 20 (1), 53-68.

Hatayama, M., Viollaz, M., Winkler, H. (2020). Jobs' Amenability to Working from Home: Evidence from Skills Surveys for 53 Countries. Policy Research Working Paper No. 9241. Washington DC: World Bank.

Horppu, M., Kuivalainen, O., Tarkiainen, A., Ellonen, H. (2008). Online satisfaction, trust and loyalty, and the impact of the offline parent brand. Journal of Product \& Brand Management 17 (6), 403-413.

Hosmer, L.T. (1995). Trust: The Connecting Link Between Organizational Theory and Philosophical Ethics. Academy of Management Review, 20, 379-403. doi: 10.5465/amr.1995.9507312923

Hough, C., Green, K., Plumlee, G. (2015). Impact of ethics environment and organizational trust on employee engagement. $J$. Legal Ethical Regulatory, 18 (3), 45.

Huff, L. ve L. Kelley (2003), Levels of Organizational Trust in Individualist Versus Collectivist Societies: A Seven Nation Study, Organization Science, 14 (1).

ILO, (2020). Working from Home: Estimating the worldwide potential. ILO Policy Brief. For more information on country measures, see the websites of acaps.org; Covid19globalemployer.com; ilo.org.

Jones, G.R. ve J. M George (1998), The Experience And Evolution Of Trust: Implications For Cooperation And Teamwork, Academy of Management Review, 23 (3).

Kennedy BP, Kawachi I, Brainerd E. (1998). The role of social capital in the Russian mortality crisis. World Development. 26 (11), 2029-2043.

Koronis, E., Ponis, S., (2018). A strategic approach to crisis management and organizational resilience. J. Bus. Strategy, 39 (1), 32-42.

Kye B, Hwang SJ. (2020) Social trust in the midst of pandemic crisis: Implications from COVID-19 of South Korea. Research in Social Stratification and Mobility. https://dx.doi.org/10.1016\%2Fj.rssm.2020.100523.

Lewicki, R.J. ve B.B.Bunker (1996), Developing and Maintaining Trust in Work Relationships. Roderick M Kramer ve Rom T.Tyler (Ed), Trust in Organizations: Frontiers of Theory and Research, 114-139, Sage Publications, London

Lewicki, R.J., McAllister, D.J. ve Bies, R.J. (1998), Trust. The Academy of Management Review, 23 (3), 438 - 458. doi: 10.5465/amr.1998.926620

Liu, J., Siu, O., Shi, K., (2010). Transformational leadership and employee well-being: the mediating role of trust in the leader and self-efficacy. Applied Psychology, 59 (3), 454-479.

Mamatoğlu N. \& Aksoy, S. (2021). COVID - 19 Salgın Sürecinde Çalışanların Motivasyon Kaynakları: Pandemi Sürecinde Neden İşe Gitmek İstenir? İş ve İnsan, (Baskıda)

Mamatoğlu, N. (2020), "Sosyal Psikolojinin Sosyal Güven Konusuna Uygulanışı", Gülden, Sayılan ve Cem Şafak Çukur (Der.), Uygulamalı Sosyal Psikoloji (Ankara: Nobel Yayınları): 351-390

Mayer, R., Davis J.H.Ve F.D Schoorman (1995), “ Integration Model Of Organizational Trust", Academy of Management Review, 20 (3).

McAllister, D. J. (1995). Affect and cognition based trust as foundations for interpersonal cooperation in organizations. Academy of Management Journal, 38 (1), 24-59. doi:10.2307/256727.
McAllister, D. (1995), Affect And Cognition Based Trust As Foundations For Interpersonal Cooperation In Organization. Academy Of Management Journal, 38 (1), 24-59

Mellinger, G. D. (1956). Interpersonal trust as a factor in communication. The Journal of Abnormal and Social Psychology, 52 (3), 304-309. doi: 10.1037/h0048100

Moliner, M.A., Sanchez, J., Rodriguez, R.M., Callarisa, L., (2007). Relationship quality with a travel agency: the influence of the postpurchase perceived value of a tourism package. Tourism and Hospitality Research, 7 (3-4), 194-211.

Morgeson, F.P., Mitchell, T.R., Liu, D., (2015). Event system theory: an event-oriented approach to the organizational sciences. Acad. Manag. Rev. 40 (4), 515-537.

Newton, K., Stolle, D., and Zmerli, S. (2018). "Social and political trust" in The Oxford handbook of social and political trust. ed. E. M. Uslaner (New York, NY, USA: Oxford University Press), 3756

Nyhan, Ronald C. and Marlowe, Herbert A. (1997). Development and psychometric properties of the organizational trust inventory, Evaluation Review, 21 (5), pp. 614-635.

Özkılıçc1, G., \& Mamatoğlu, N. (2021). Yeni Koronavirüs (COVID-19) Salgını: Tutumlar, Algılar Ve Siyasi Lider Stili Tercihi. Alternatif Politika, 13 (1), 208-246

Putnam, R. D. (2000). Bowling Alone: The Collapse and Revival of American Community. New York: Simon \& Schuster

Read, W. H. (1962). Upward communication in industrial hierarchies. Human Relations, 15, 3-15. doi: 10.1177/001872676201500101

Schiefer D, van der Noll J. (2017). The essentials of social cohesion: A literature review. Social Indicators Research. 132, $579-603$

Shockley-Zalabak, P., Ellis, K., Winograd, G., (2000). Organizational trust: what it means, why it matters. Organization Development Journal, 18 (4), 35-48.

Siegrist M, Gutscher H, Earle TC. (2005) Perception of risk: The influence of general trust, and general confidence. Journal of Risk Research. 8 (2):145-56.

Six, F. (2008). The Trouble with Trust: The Dynamics of Interpersonal Trust Building. Edward Elgar Publishing.

Stolle, D. (2001). "Clubs and congregations: the benefits of joining an association" in Trust in society. ed. K. S. Cook (New York, NY, USA: Russell Sage Foundation), 202-244.

Su K, Liu H, Zhang H. (2019). Board size, social trust, and corporate risk taking: evidence from China. Managerial and Decision Economics. 40 (6):596-609.

Tokgöz, Emrah ve Seymen, Oya A. (2013). Örgütsel güven, örgütsel özdeşleşme ve örgütsel vatandaşlık davranışı arasındaki ilişki: Bir devlet hastanesinde araştırma, Öneri Dergisi, 10 (39), 61-76.

Tourigny, L., Han, J., Baba, V.V., Pan, P. (2019). Ethical leadership and corporate social responsibility in China: a multilevel study of their effects on trust and organizational citizenship behavior. J. Bus. Ethics 158 (2), 427-440.

Van Bavel JJ, Baicker K, Boggio PS, Capraro V, Cichocka A. (2020). Using social and behavioural science to support COVID19 pandemic response. Nature Human Behaviour. 4:460-471. https://doi.org/ 10.1038/s41562-020-0884-z PMID: 32355299

Yilmaz, A. and Atalay, C. (2009). A theoretical analysis on the concept of trust in organizational life. European Journal of Social Sciences, 8 (2), 341-352. 